\title{
Clinical predictors of symptom resolution for children and adolescents with sport-related concussion
}

\author{
David R. Howell, PhD, 1,2 Morgan N. Potter, BA, 1,2 Michael W. Kirkwood, PhD,,34 \\ Pamela E. Wilson, MD, ${ }^{3,4}$ Aaron J. Provance, MD, ${ }^{1,2}$ and Julie C. Wilson, MD ${ }^{1,2}$ \\ 'Sports Medicine Center and 'Rehabilitation Medicine, Children's Hospital Colorado; and 2Department of Orthopedics and \\ ${ }^{3}$ Department of Physical Medicine and Rehabilitation, University of Colorado School of Medicine, Aurora, Colorado
}

\begin{abstract}
OBJECTIVE The goal of this study was to determine which variables assessed during an initial clinical evaluation for concussion are independently associated with time until symptom resolution among pediatric patients.

METHODS Data collected from a prospective clinical registry of pediatric patients with concussion were analyzed. The primary outcome variable was time from injury until symptom resolution. Predictor variables assessed within 10 days after injury included preinjury factors, Health and Behavior Inventory scores, headache severity, and balance, vestibular, and oculomotor test performances. The researchers used univariate Cox proportional models to identify potential predictors of symptom resolution time and constructed a multivariate Cox proportional hazards model in which total duration of concussion symptoms remained the outcome variable.
\end{abstract}

RESULTS The sample consisted of 351 patients (33\% female, mean age $14.6 \pm 2.2$ years, evaluated $5.6 \pm 2.6$ days after concussion). Univariate Cox proportional hazards models indicated that several variables were associated with a longer duration of symptoms, including headache severity (hazard ratio [HR] $0.90[95 \% \mathrm{Cl} 0.85-0.96]$ ), headache frequency ( $\mathrm{HR} 0.83$ [95\% $\mathrm{Cl} 0.71-0.96]$ ), confusion ( $\mathrm{HR} 0.79$ [95\% $\mathrm{Cl} 0.69-0.92]$ ), forgetfulness ( $\mathrm{HR} 0.79[95 \% \mathrm{Cl}$ 0.68-0.92]), attention difficulties ( $\mathrm{HR} 0.83$ [95\% $\mathrm{Cl} 0.72-0.96])$, trouble remembering ( $\mathrm{HR} 0.84$ [95\% $\mathrm{Cl} 0.72-0.98]$ ), getting tired often (HR 0.86 [95\% Cl 0.76-0.97]), getting tired easily (HR 0.86 [95\% Cl 0.76-0.98]), dizziness (HR 0.86 $[95 \% \mathrm{Cl} 0.75-0.99])$, and abnormal performance on the Romberg test ( $\mathrm{HR} 0.59[95 \% \mathrm{Cl} 0.40-0.85])$. A multivariate Cox proportional hazards model indicated that an abnormal performance on the Romberg test was independently associated with a longer duration of symptoms ( $\mathrm{HR} 0.65[95 \% \mathrm{Cl} 0.44-0.98] ; p=0.038)$.

CONCLUSIONS For children and adolescents evaluated within 10 days after receiving a concussion, abnormal performance on the Romberg test was independently associated with a longer duration of symptoms during recovery. In line with findings of other recent studies investigating predictors of symptom resolution, postural stability tests may provide useful prognostic information for sports medicine clinicians.

https://thejns.org/doi/abs/10.3171/2018.11.PEDS18626

KEYWORDS pediatric concussion; mild traumatic brain injury; trauma; Romberg test; postural balance; recovery

$\mathrm{C}$ ONCUSSIONS are defined as a mild form of traumatic brain injury (mTBI) induced by biomechanical forces that result in acute neurological dysfunction. The injury typically resolves within a few days or weeks. ${ }^{32}$ However, a notable minority of patients experience persistent postconcussion symptoms, which continue for many weeks or months after the injury. ${ }^{21,34}$ Early prognosis of recovery potential and identification of those patients likely to experience persistent symptoms remain challenging for clinicians, as a wide array of premorbid conditions, injury characteristics, and functional factors have been identified in previous works. ${ }^{22,30,37,44}$
Identifying a set of ecologically valid variables that can be used to predict symptom recovery as well as expected timelines for returning to play or to school can help facilitate early intervention pathways. This is a challenging concept, particularly with regard to children and adolescents, since these patients may be more vulnerable to prolonged recovery than adults ${ }^{3,19}$ and because recovery timelines have primarily been established using cohorts of adult participants. ${ }^{31}$ Previously, in the pediatric emergency department (ED) setting, researchers have observed that a combination of demographic, medical history, symptom, and postural control variables can be used successfully to

ABBREVIATIONS ADHD = attention-deficit/hyperactivity disorder; BESS = Balance Error Scoring System; ED = emergency department; HBI = Health and Behavior Inventory; $\mathrm{mTBI}=$ mild traumatic brain injury; NPC = near point of convergence; VIF = variance inflation factor.

SUBMITTED October 11, 2018. ACCEPTED November 29, 2018.

INCLUDE WHEN CITING Published online April 16, 2019; DOI: 10.3171/2018.11.PEDS18626. 
predict those patients who are likely to experience concussion symptoms longer than 28 days after injury. ${ }^{44}$ In addition, recently investigators applied this approach to the sports medicine setting and were able to successfully identify those patients at risk for persistent symptoms. ${ }^{20}$

A particularly vulnerable time in life for developing persistent symptoms after a concussion is the teenage years, during which girls may carry a higher risk than boys. ${ }^{22} \mathrm{Sev}-$ eral other noninjury factors that have been associated with concussion recovery time include previous concussions, attention-deficit/hyperactivity disorder (ADHD), learning disability, prior psychiatric history, and migraine history. ${ }^{22}$ In addition, some variables identified during initial clinical evaluations, such as acute headache, acute dizziness, poor initial balance, and acute neuropsychological deficits, are associated with symptom duration. ${ }^{22}$ While total symptom severity has been noted as a predictor of symptom recovery time, ${ }^{17,35,37,38}$ few studies have evaluated whether the frequency of symptoms experienced after a concussion can be used to predict symptom resolution. The Health and Behavior Inventory (HBI) is included as a common data element for sport concussion ${ }^{6}$ and pediatric TBI, ${ }^{12}$ and it has been developed specifically for the pediatric population by assessing the frequency of different symptoms associated with an mTBI. ${ }^{2,14}$ In addition to symptom frequency and noninjury factors, postural stability assessments ${ }^{44}$ and tests of vestibular-oculomotor abilities ${ }^{9,10,15,30}$ may also provide predictive value to determine the length of time that will be required for symptom resolution.

The purpose of this investigation was to determine which variables assessed as a part of a routine clinical concussion evaluation would be independently associated with the duration of symptom resolution among pediatric patients who were evaluated after sport-related concussion by a sports medicine physician. We hypothesized that patients' preinjury mental health conditions and prior concussion histories as well as a greater frequency of concussion symptoms within the first 10 days after a concussion would be independently associated with symptom duration.

\section{Methods}

\section{Study Design and Participants}

We conducted an analysis of data collected from a prospective clinical registry of children and adolescents with concussion who had been seen for care at the Children's Hospital Colorado Sports Medicine Center between January 1, 2015, and August 31, 2017, and returned for care according to their individual clinical needs until they no longer required it or were referred to a different specialist. Patients were required to complete standardized questionnaires at each clinical visit and to undergo a variety of standardized tests administered by their physician. Responses to the questions and test results were reviewed with the family at the evaluation, which minimized missing data. Data were input into the electronic medical record immediately following the visit. We then reviewed each medical record to input relevant data, ensuring data quality. Inclusion criteria consisted of being seen and evaluated within the first 10 days after concussion and being 18 years of age or younger. We excluded patients who sustained a concus- sion from a non-sport-related mechanism involving a highvelocity impact (for example, a motor vehicle accident or fall from a height), presented with traumatic abnormalities on neuroimaging, or returned for care following a second head injury before clearance from the initial injury. All diagnoses of concussion were made by a board-certified sports medicine physician and were consistent with guidelines expressed in the international consensus statement on concussion in sport. ${ }^{33}$ Management decisions during recovery were also consistent with those outlined in these consensus guidelines ${ }^{33}$ in which patients were given individualized recommendations about school, physical activity, and cognitive activity based on the type of symptoms present and the activities that exacerbated their symptoms. Patients did not receive clearance from the physician to return to full sport participation until they no longer reported concussion symptoms and had completed a stepwise return-to-play protocol. ${ }^{33}$ Prior to our conducting this study, the local institutional review board approved the protocol.

\section{Clinical Evaluation}

All patients completed a standardized intake form and a clinical evaluation that included several vestibular and oculomotor tests. The intake form required patients to report whether they had previously experienced a diagnosed concussion in their lifetime, the sport they were competing in at the time of injury (if applicable), and previous diagnoses of ADHD, learning disabilities, anxiety, depression, and migraine. Also recorded was whether patients received neuroimaging as a part of their clinical evaluation. Patients responded to several questions pertaining to their current status, including whether they were currently experiencing a headache (and if so, the severity ranked on a Likert-like scale ranging from 0 indicating no pain to 10 indicating the most severe pain) and if they had been experiencing sleep difficulties since the injury occurred; they also filled out the HBI. ${ }^{2}$ The HBI is a 20 -item scale that measures the frequency of different symptoms that are associated with concussion. Youths completed the child version of the HBI by rating the frequency of symptoms experienced on a 4-point Likert scale as 0 (never), 1 (rarely), 2 (sometimes), and 3 (often). ${ }^{2}$ In addition to individual symptom ratings, a total symptom score was calculated as the sum of all items, in which higher scores indicate more frequent symptoms.

To assess balance, vestibular, and ocular function, the clinicians administered the Balance Error Scoring System (BESS), Romberg, tandem gait, gaze stability, and near point of convergence (NPC) tests. During the BESS, patients completed three different stance conditions (doubleleg, single-leg, and tandem) on firm ground and on a foam pad for 20 seconds. During the double-leg stance, patients stood with their feet positioned side by side. For the singleleg stance, participants stood on the foot that they identified as their nondominant kicking leg. During the tandem stance, participants stood with their feet positioned so that the nondominant foot was placed directly behind the dominant foot. The patients were instructed to remain with their eyes closed and their hands on their hips for the duration of the trial., ${ }^{5,1324}$ Physicians or certified athletic trainers administering the test counted the total number of 
errors committed during the trial, with a maximum of 10 errors per condition.

The tandem gait, Romberg, gaze stability, and NPC test results were analyzed as dichotomous variables (normal vs abnormal). During the tandem gait test, patients were instructed to walk heel to toe in a straight line across the examination room or down a hallway. A normal test performance was identified as being able to walk without significant loss of balance and to maintain heel-to-toe contact throughout the test. Excessive upper-body movement observed while lower extremities successfully completed the task was identified as an abnormal test performance, as this may indicate exaggeration and symptom feigning.

During the Romberg test, patients stood with feet together and eyes closed while the clinician monitored their stance. A normal Romberg test performance was defined as patients being able to hold still without significant loss of balance (signified by opening eyes, lifting foot, or falling out of position). An abnormal test result was defined as loss of balance or an exaggerated movement during the test. As with the tandem gait test, increased upper-body movement observed while the feet remained still was classified as an abnormal test result.

During the gaze stability test, patients held their thumb at arm's length in front of their faces. They were instructed to focus on the thumb and turn their heads from side to side horizontally while their eyes maintained focus on the thumb. This process was then repeated with the head moving in the vertical plane of movement. An abnormal test result was recorded if patients reported an increase in dizziness, nausea, headache, or visual problems with either task, while a normal test result was recorded if they experienced no increase in concussion symptoms. Finally, to determine NPC, patients focused on a target such as a pen tip. The target was slowly brought to the tip of the patient's nose from a distance; once patients reported diplopia or the clinician observed outward deviation of the eye, movement of the target was stopped and the distance was measured. Consistent with prior work, an NPC of $>5$ cm was considered abnormal. ${ }^{18,41}$

\section{Outcome and Predictor Variables}

Our primary outcome variable was time from concussion until symptom resolution. This was determined at each clinical evaluation in which patients were assessed as to whether they were continuing to experience concussion symptoms. Patients were followed up until they no longer required care because their symptoms resolved or because they were lost to follow-up. Symptom resolution time was determined as the time elapsed from injury until the clinic visit at which patients no longer reported experiencing concussion-related symptoms. If during the last recorded visit patients still indicated they were symptomatic, they were considered lost to follow-up and their data were included in the time-to-event analysis as censored data.

We assessed demographic, medical history, and injury characteristic data using standardized intake forms. We used the HBI to assess overall symptom frequency as well as specific frequencies of all 20 items included within the HBI. We used pass/fail criteria from the tandem gait, Romberg, gaze stability, and NPC tests, as well as stan- dardized scoring criteria for the BESS test. ${ }^{5}$ The HBI, BESS, tandem gait, gaze stability, and NPC tests are all included as assessment components of the National Institutes of Health Common Data Elements for sport concussion $^{6}$ (https://www.commondataelements.ninds.nih.gov/ SRC.aspx\#tab=Data_Standards), and thus these tests were included as our primary predictor variables.

\section{Statistical Analysis}

Continuous variables are presented as means \pm standard deviations and categorical variables are presented as percentages. We assessed demographic factors, medical history, injury characteristics, symptom frequency, and balance, vestibular, and ocular function of patients using descriptive statistics. For the univariate analysis of time to symptom resolution, we constructed univariate Cox proportional models with time to symptom resolution as the outcome and each clinical variable as a separate predictor variable. To adjust for confounders, we selected predictor variables with an a priori determined univariate significance level of $p<0.05$ to construct a multivariate Cox proportional hazards model in which total duration of concussion symptoms remained the outcome variable. We assessed collinearity using condition indices and corresponding variance inflation factors (VIFs). A condition index $>30$ was determined to require individual collinearity assessments, which were performed using VIFs. Collinearity between two variables was detected using a VIF $>2.5 .35,37$ Finally, we performed a sensitivity multivariable analysis with Romberg test performance as the predictor variable, and sex, preinjury mental health conditions, history of prior concussion, and age as covariates in the model. Statistical significance was set at $\alpha<0.05$ and all tests were two-sided. Statistical analyses were performed using Stata version 15 (StataCorp).

\section{Results}

During the study period, 934 patients were seen by clinicians for a potential concussion. We excluded 583 participants after we had applied inclusion and exclusion criteria to ensure a relatively homogenous sample of children and adolescents in our sample (excluded: 7 patients without concussion diagnosis; 318 patients seen by a clinician $>10$ days postinjury; 1 patient $>18$ years of age; 229 patients whose concussion was due to a non-sport-related injury mechanism; 2 patients in whom a traumatic abnormality was evident on neuroimaging; 10 patients who returned for care following a second head injury prior to clearance from the initial injury; and 32 patients who were asymptomatic at the time of initial evaluation [some patients were excluded for more than one reason]). Thus, 351 participants were included in our analysis. The most common sports activity during which patients reported sustaining a concussion included American football (25\%), soccer $(24 \%)$, lacrosse $(9 \%)$, basketball $(8 \%)$, ice hockey $(5 \%)$, baseball (4\%), and volleyball (3\%). Sixty-eight patients $(19 \%)$ underwent neuroimaging, including $56(16 \%)$ who received a CT scan and 14 (4\%) who received an MRI.

The children and adolescents included in the study (median age 14.9 years [interquartile range $\{I Q R\}$ 13.1-16.1 
TABLE 1. Characteristics of 351 patients at the initial clinical evaluation and corresponding univariate associations with symptom duration

\begin{tabular}{lccc}
\hline \multicolumn{1}{c}{ Characteristic } & $\begin{array}{c}\text { No. of } \\
\text { Patients (\%) }\end{array}$ & $\begin{array}{c}\text { Univariate Cox HR } \\
(95 \% \mathrm{Cl})\end{array}$ & $\begin{array}{c}\mathrm{p} \\
\text { Value }\end{array}$ \\
\hline Sex (female) & $116(33)$ & $1.37(0.99-1.89)$ & 0.06 \\
\hline Age (yrs) ${ }^{*}$ & $14.6 \pm 2.2$ & $0.97(0.91-1.03)$ & 0.35 \\
\hline LOC at time of injury & $56(16)$ & $0.87(0.58-1.30)$ & 0.50 \\
\hline Pre-existing history & & & \\
\hline Concussion & $163(46)$ & $0.89(0.66-1.20)$ & 0.45 \\
\hline ADHD & $44(13)$ & $1.38(0.89-2.13)$ & 0.15 \\
\hline Learning disability & $31(9)$ & $0.82(0.49-1.37)$ & 0.45 \\
\hline Anxiety & $18(5)$ & $1.08(0.60-1.94)$ & 0.80 \\
\hline Depression & $6(2)$ & $0.65(0.16-2.64)$ & 0.55 \\
\hline Migraine or headaches & $96(27)$ & $1.05(0.76-1.46)$ & 0.76 \\
\hline LOC = loss of consciousness. & & \\
* Continuous variable presented as mean \pm SD. &
\end{tabular}

years]) were evaluated at a median of 6 days (IQR 3-8 days) after concussion and reported that their symptoms had resolved at a median of 23 days (IQR 16-32 days) postinjury. Almost half of the patients reported a history of concussion, while other preinjury health conditions were reported less often (Table 1). The most commonly reported symptoms by patients at the initial visit were headaches, difficulty paying attention, difficulty concentrating, and getting distracted easily (Tables 2 and 3). The most common abnormal vestibular or oculomotor test result was symptom provocation brought on by gaze stability testing, while fewer patients exhibited an abnormal Romberg test performance, demonstrated an abnormal tandem gait, or had an abnormal NPC (Tables 4 and 5).

Results from the univariate Cox proportional hazards models indicated that headache severity, headache frequency, confusion, forgetfulness, attention difficulties, trouble remembering, getting tired often, getting tired easily, dizziness, and an abnormal Romberg test performance were associated with a longer duration of symptoms (Tables 2-5). Each of these variables was included in the multivariate Cox model, with the exception of headache frequency (VIF 3.42) and getting tired easily (VIF 3.32) due to their collinearity with headache severity and getting tired often, respectively. After adjusting for confounders, the multivariate Cox proportional hazards model indicated that an abnormal Romberg test performance was independently associated with a longer symptom duration (Table 6). Thus, time to symptom resolution was significantly longer in those patients who demonstrated an abnormal Romberg test performance at the initial clinical evaluation than in those patients who did not (Fig. 1; median symptom resolution time 17 days [IQR 10-26 days] vs 10.5 days [IQR 6-21 days] after concussion). The proportion of patients who were injured during soccer and demonstrated an abnormal Romberg test performance was somewhat higher, but not significantly different from those who were injured during football $(25 \%$ vs $14 \%$; $=0.12$ ). Sensitivity multivariable analysis indicated that after adjusting for patient sex and age, preinjury mental
TABLE 2. Self-reported headache, sleep, and overall HBI score during the initial clinical evaluation and corresponding univariate associations with symptom duration

\begin{tabular}{lccc}
\hline \multicolumn{1}{c}{ Variable } & $\begin{array}{c}\text { No. of Patients (\%) } \\
\text { or Median (IQR) }\end{array}$ & $\begin{array}{c}\text { Univariate Cox HR } \\
(95 \% \mathrm{Cl})\end{array}$ & $\begin{array}{c}\mathrm{p} \\
\text { Value }\end{array}$ \\
\hline Headache severity & $4(2-6)$ & $0.90(0.85-0.96)$ & 0.001 \\
\hline $\begin{array}{c}\text { Sleep problems } \\
\text { since injury }\end{array}$ & $110(31)$ & $0.75(0.54-1.04)$ & 0.08 \\
\hline Overall HBI score & $18(10-27)$ & $0.99(0.98-1.00)$ & 0.07 \\
\hline
\end{tabular}

Boldface type indicates statistical significance $(p<0.05)$.

health conditions, and history of concussion, an abnormal Romberg test performance was independently associated with longer symptom duration (hazard ratio [HR] 0.59 [95\% CI 0.40-0.88]; $\mathrm{p}=0.009$ ).

\section{Discussion}

In the current study we examined the relationship between a comprehensive set of pragmatic variables collected during a clinical sports medicine evaluation and duration of postconcussion symptoms. Romberg test performance was the strongest predictor of symptom duration among all of the noninjury, symptom frequency, vestibular function, oculomotor function, and postural stability factors that we examined. This finding is interesting in light of previous research that showed that the Romberg test may not be sensitive enough to identify vestibular dysfunction. ${ }^{23}$ However, in our sample, patients were classified as having abnormal test performance when they demonstrated significant loss of balance or increased upper-body movement, which can be a sign of exaggeration or feigning of symptoms. ${ }^{42}$ Thus, it is difficult to determine whether patients who demonstrated abnormal performance on the Romberg test had postural instability due to a physiological deficit, noncredible effort, or exaggerated movements during the test. Therefore, there may be multiple reasons underlying the independent association between abnormal Romberg test performance and longer symptom duration in our cohort of youths with concussion. Regardless, the results suggest that clinicians may consider implementing the Romberg test as a screen for potential prolonged recovery in child and adolescent athletes.

It has been reported that the Romberg test is used as frequently as other standard concussion testing techniques, such as the Standardized Assessment of Concussion or computerized neuropsychological testing among athletic trainers..$^{28}$ Recent work has indicated that postural instability, defined as more than three errors during the tandem stance of the BESS test, is associated with prolonged symptom duration in patients seen in both the ED and sports medicine clinic settings. ${ }^{20,44}$ In addition to postural instability assessment, the Romberg test may also serve as a method to determine if patients are exaggerating their postinjury deficits in a manner that reflects balance dysfunction. ${ }^{42}$ The idea that some youths may exaggerate or feign symptoms after concussion has been studied in the context of neuropsychological testing and symptom reporting, ${ }^{1,7,26}$ but it has not received substantial 
TABLE 3. Responses of patients to HBI questions during the initial clinical evaluation and corresponding univariate associations with symptom duration

\begin{tabular}{|c|c|c|c|c|c|c|}
\hline HBI Item & Never & Rarely & Sometimes & Often & Univariate Cox HR $(95 \%$ Cl) & $\mathrm{p}$ Value \\
\hline Trouble paying attention & $77(23 \%)$ & $81(24 \%)$ & $126(37 \%)$ & $59(17 \%)$ & $0.83(0.72-0.96)$ & 0.01 \\
\hline Easily distracted & $87(26 \%)$ & $95(28 \%)$ & $93(27 \%)$ & $65(19 \%)$ & $0.91(0.80-1.04)$ & 0.19 \\
\hline Hard time concentrating & $82(24 \%)$ & $83(25 \%)$ & $101(30 \%)$ & $72(21 \%)$ & $0.88(0.77-1.01)$ & 0.06 \\
\hline Problems remembering what people tell me & $152(45 \%)$ & $98(29 \%)$ & $68(20 \%)$ & $23(7 \%)$ & $0.84(0.72-0.98)$ & 0.03 \\
\hline Problems following directions & $203(60 \%)$ & $84(25 \%)$ & $44(13 \%)$ & $9(3 \%)$ & $0.95(0.80-1.13)$ & 0.57 \\
\hline Daydream too much & $185(54 \%)$ & $81(24 \%)$ & $54(16 \%)$ & $21(6 \%)$ & $0.92(0.79-1.08)$ & 0.32 \\
\hline Confused & $143(42 \%)$ & $84(25 \%)$ & $84(25 \%)$ & $30(9 \%)$ & $0.79(0.69-0.92)$ & 0.002 \\
\hline Forget things & $128(38 \%)$ & $105(31 \%)$ & $73(22 \%)$ & $33(10 \%)$ & $0.79(0.68-0.92)$ & 0.002 \\
\hline Problems finishing things & $181(54 \%)$ & $90(27 \%)$ & $55(16 \%)$ & $12(4 \%)$ & $0.92(0.78-1.09)$ & 0.33 \\
\hline Trouble figuring things out & $189(56 \%)$ & $86(26 \%)$ & $49(15 \%)$ & $11(3 \%)$ & $0.91(0.77-1.08)$ & 0.29 \\
\hline Hard for me to learn new things & $213(64 \%)$ & $65(19 \%)$ & $45(13 \%)$ & $11(3 \%)$ & $0.87(0.85-1.20)$ & 0.87 \\
\hline Headaches & $26(8 \%)$ & $46(13 \%)$ & $91(26 \%)$ & $181(53 \%)$ & $0.83(0.71-0.96)$ & 0.01 \\
\hline Dizzy & $113(33 \%)$ & $89(26 \%)$ & $91(27 \%)$ & $47(14 \%)$ & $0.86(0.75-0.99)$ & 0.04 \\
\hline The room is spinning & $218(64 \%)$ & $77(23 \%)$ & $39(11 \%)$ & $7(2 \%)$ & $0.82(0.66-1.02)$ & 0.08 \\
\hline I am going to faint & $265(77 \%)$ & $57(17 \%)$ & $13(4 \%)$ & $8(2 \%)$ & $0.90(0.73-1.10)$ & 0.31 \\
\hline Blurry vision & $210(62 \%)$ & $71(21 \%)$ & $40(12 \%)$ & $20(6 \%)$ & $0.89(0.76-1.05)$ & 0.18 \\
\hline Double vision & $296(87 \%)$ & $31(9 \%)$ & $13(4 \%)$ & $1(0 \%)$ & $0.79(0.57-1.10)$ & 0.16 \\
\hline Sick to my stomach & $166(49 \%)$ & $80(23 \%)$ & $65(19 \%)$ & $31(9 \%)$ & $0.93(0.80-1.08)$ & 0.35 \\
\hline Tired a lot & $70(20 \%)$ & $73(21 \%)$ & $81(24 \%)$ & $119(35 \%)$ & $0.86(0.76-0.97)$ & 0.02 \\
\hline Tired easily & $76(22 \%)$ & $75(22 \%)$ & $86(25 \%)$ & $104(31 \%)$ & $0.86(0.76-0.98)$ & 0.03 \\
\hline
\end{tabular}

Unless otherwise indicated, values represent numbers of patients (\%). Boldface type indicates statistical significance $(p<0.05)$.

attention with regard to postural stability tests. Previous work suggests that approximately $23 \%$ of children failed a well-validated performance validity test after a concussion. ${ }^{42}$ Taken together with our findings, it is plausible that some individuals truly cannot control their balance when evaluated, resulting in an abnormal performance on the Romberg test, while others may have exaggerated their movements. Regardless, both sets of individuals may require special attention soon after concussion, as they may be at an increased risk for experiencing prolonged symptoms. Clinical screening using the Romberg test soon after concussion may allow clinicians to identify those patients who may experience persistent symptoms. Identifying these high-risk individuals early after injury may allow for their referral to physical therapy or a mental health provider, depending on the clinical scenario, to reduce concussion symptoms, as has been observed previously. ${ }^{25,43}$ Of course, understanding whether the abnormality represents a neurological injury or exaggeration or feigning of symptoms is key to making appropriate referrals, including the consideration of neuroimaging. Neuropsychology may be particularly useful in detecting and beginning to address noncredible effort. ${ }^{8}$ The Romberg test may not necessarily indicate an intentional exaggeration of postinjury deficits, as it may indicate neurological injury resulting in postural instability or external factors that affect injury presentation. After identification of an abnormal test result, clinical expertise should guide management strategies related to potential mechanisms for the abnormal performance.

In comparison to other studies of patients seen for care in specialty concussion programs, our results indicate similar durations of symptom resolution among children and adolescents. Heyer and colleagues described a median symptom recovery time of 18 days, but also reported that female sex, loss of consciousness at the time of injury, symptom severity, premorbid headache, and days from injury to evaluation were each associated with protracted recovery. ${ }^{16}$ Interestingly, none of these factors were associated with prolonged recovery in our sample of individuals. This may be due to the timeline differences between studies, as Heyer and colleagues included individuals up to 30

TABLE 4. Results from the BESS administered within 10 days after injury demonstrating clinical balance and corresponding univariate associations with symptom duration

\begin{tabular}{lcccc}
\hline \multicolumn{1}{c}{ Variable } & $\begin{array}{c}\text { Median } \\
\text { Score (IQR) }\end{array}$ & Range & $\begin{array}{c}\text { Univariate Cox } \\
\mathrm{HR}(95 \% \mathrm{Cl})\end{array}$ & $\begin{array}{c}\mathrm{p} \\
\text { Value }\end{array}$ \\
\hline $\begin{array}{l}\text { Firm surface double } \\
\text { stance }\end{array}$ & $0(0-0)$ & $0-10$ & $0.97(0.89-1.06)$ & 0.54 \\
\hline $\begin{array}{c}\text { Firm surface single } \\
\text { stance }\end{array}$ & $4(2-7)$ & $0-10$ & $0.97(0.93-1.02)$ & 0.23 \\
\hline $\begin{array}{c}\text { Firm surface tandem } \\
\text { stance }\end{array}$ & $2(1-4)$ & $0-10$ & $0.98(0.94-1.03)$ & 0.51 \\
\hline $\begin{array}{c}\text { Foam surface double } \\
\text { stance }\end{array}$ & $0(0-1)$ & $0-10$ & $0.96(0.86-1.04)$ & 0.29 \\
\hline $\begin{array}{c}\text { Foam surface single } \\
\text { stance }\end{array}$ & $8(6-10)$ & $0-10$ & $1.00(0.97-1.04)$ & 0.82 \\
\hline $\begin{array}{c}\text { Foam surface tandem } \\
\text { stance }\end{array}$ & $5(3-9)$ & $0-10$ & $1.01(0.98-1.06)$ & 0.47 \\
\hline
\end{tabular}


TABLE 5. Results from vestibular tests administered within 10 days after injury and corresponding univariate associations with symptom duration

\begin{tabular}{lcccc}
\hline \multicolumn{1}{c}{ Test } & No. of Tests w/ Abnormal Performance & \% Abnormal Performances & Univariate Cox HR (95\% Cl) & $\mathrm{p} \mathrm{Value}$ \\
\hline Tandem gait & 49 & 14 & $0.67(0.44-1.02)$ & 0.07 \\
\hline Romberg & 68 & 19 & $0.59(0.40-0.85)$ & 0.006 \\
\hline Gaze stability & 162 & 46 & $0.76(0.56-1.02)$ \\
\hline Near point of convergence & 53 & 15 & 0.07 \\
\hline
\end{tabular}

Boldface type indicates statistical significance $(p<0.05)$.

days after injury, while we only examined those seen within the first 10 days of injury. In patients evaluated within 14 days after injury, Master and colleagues found that balance deficits during tandem gait testing were associated with prolonged recovery. ${ }^{30}$ Thus, balance deficits may be more readily predictive of prolonged recovery when tested sooner after injury ( 2 weeks in that study). Furthermore, our results suggest that almost all patients report symptom resolution within approximately 4 months after injury, which is valuable for clinicians to recognize as they provide counseling for patients regarding the expected duration of recovery. Of course, 4 months likely represents a biased population seen in a concussion specialty clinic, so it may not represent the natural history of concussion.

Although previous work has identified several prognostic factors for concussion recovery, ${ }^{22,30,37,44}$ our results did not indicate that premorbid conditions, injury characteristics, or functional factors relate to symptom resolution time. This may be due to the fact that we focused only on sport-related injuries that were evaluated in a specialty care sports medicine clinic. As such, postinjury presentation of the patients in our investigation may differ from that of patients seen in an ED setting, for example. Although not significant on the multivariate tests, there were several symptoms that were associated with symptom duration on the univariate evaluation. Specifically, both headache severity and frequency as well as dizziness were associated with longer symptom duration. Previous work has also

TABLE 6. Results of the multivariate Cox regression model for all patients, using predictor variables with univariate Cox regression $p$ values $<0.05$

\begin{tabular}{|c|c|c|c|c|}
\hline Predictor Variable & $\mathrm{HR}$ & SE & $95 \% \mathrm{Cl}$ & p Value \\
\hline Headache severity & 0.94 & 0.03 & $0.88-1.01$ & 0.08 \\
\hline $\begin{array}{l}\text { Abnormal performance on Romberg } \\
\text { test }\end{array}$ & 0.65 & 0.13 & $0.44-0.98$ & 0.04 \\
\hline “I get confused" frequency rating & 0.89 & 0.10 & $0.72-1.11$ & 0.31 \\
\hline "I forget things" frequency rating & 0.92 & 0.12 & $0.71-1.19$ & 0.53 \\
\hline $\begin{array}{l}\text { "I have trouble paying attention" } \\
\text { frequency rating }\end{array}$ & 0.97 & 0.09 & $0.81-1.16$ & 0.73 \\
\hline "I get tired a lot" frequency rating & 0.99 & 0.08 & $0.85-1.15$ & 0.85 \\
\hline $\begin{array}{l}\text { "I have problems remembering what } \\
\text { people tell me" frequency rating }\end{array}$ & 1.02 & 0.13 & $0.80-1.30$ & 0.90 \\
\hline "I feel dizzy" frequency rating & 1.02 & 0.09 & $0.86-1.21$ & 0.80 \\
\hline
\end{tabular}

An abnormal finding on the Romberg test was independently associated with longer symptom duration. Boldface type indicates statistical significance $(p<$ 0.05). documented that acute headache ${ }^{39,44}$ and dizziness ${ }^{9,11,27}$ are associated with longer symptom duration. As such, determining individual symptoms associated with prolonged recovery may allow for a more individualized approach to identifying patients at risk for developing persistent postconcussion symptoms and for tailoring treatments around their most bothersome findings. Interestingly, we did not find an association between several established predictors of prolonged recovery and symptom duration time, such as female sex,,${ }^{4,44}$ anxiety, ${ }^{20} \mathrm{ADHD},{ }^{40}$ prior concussions, ${ }^{36,46}$ or younger age..$^{29,45}$ Our findings may reflect the specific population of individuals seen in our clinic and should be placed in the context of the overall body of literature. As preinjury mental health conditions, prior concussions, and being a teenager or female seem to be the most consistent predictors of persistent concussion symptom risk, ${ }^{22}$ future studies should continue to develop prospective methods to better understand individual factors related to recovery time following concussion.

\section{Limitations}

Our study had several limitations, and our findings should be considered in light of them.

The analysis of data collected from a prospective clinical registry of children reduces our ability to control for factors related to postinjury treatment and the timing of when clinical visits occurred. Furthermore, as we drew from a sample of athletes who presented to a sports medicine specialty clinic, the injuries sustained by our sample of patients may not accurately represent similar injuries that occur within the immediate geographic area or in other geographic areas.

We applied a strict set of inclusion and exclusion criteria in an attempt to ensure some level of homogeneity among patients, but our results may not be generalizable to other populations, such as older or younger individuals, those who sustained an injury as a result of a non-sport-related event, or those seen for care in other clinical settings.

\section{Conclusions}

For adolescent and child patients assessed within 10 days after concussion, an abnormal performance on the Romberg test was independently associated with longer symptom duration during recovery. This is in line with findings of other recent studies investigating early predictors of symptom resolution, which demonstrate that postural instability appears to provide valuable prognostic information for sports medicine clinicians. As the Romberg test may identify both those patients who are experiencing 


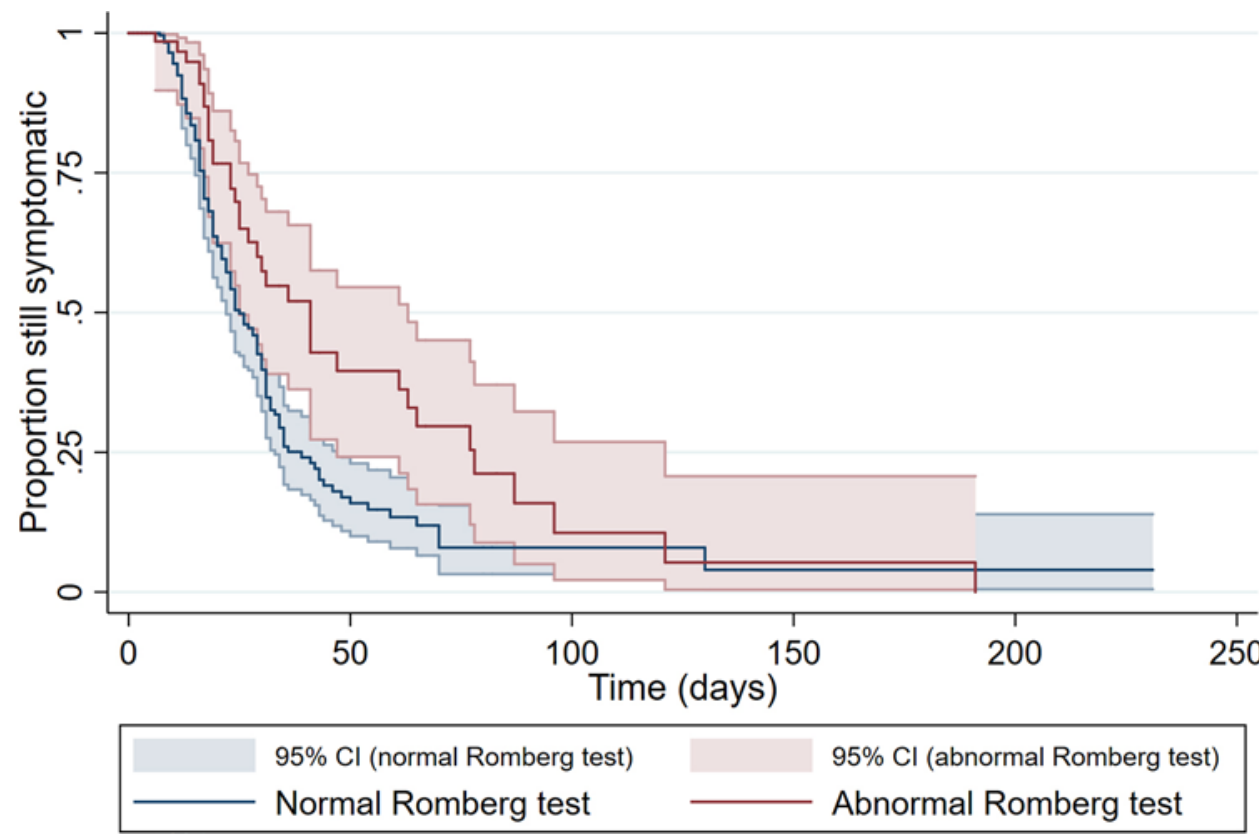

FIG. 1. Kaplan-Meier curve for duration of symptoms, grouped by those patients who displayed normal and abnormal performance on the Romberg test when assessed within 10 days after injury. Shaded areas represent $95 \% \mathrm{Cls}$. Figure is available in color online only.

postural instability and those who are exaggerating their symptoms, abnormal test performance within the first 10 days after a concussion may alert clinicians to recognize pediatric patients who are at risk for developing persistent symptoms.

\section{References}

1. Araujo GC, Antonini TN, Monahan K, Gelfius C, Klamar $\mathrm{K}$, Potts M, et al: The relationship between suboptimal effort and post-concussion symptoms in children and adolescents with mild traumatic brain injury. Clin Neuropsychol 28:786-801, 2014

2. Ayr LK, Yeates KO, Taylor HG, Browne M: Dimensions of postconcussive symptoms in children with mild traumatic brain injuries. J Int Neuropsychol Soc 15:19-30, 2009

3. Baillargeon A, Lassonde M, Leclerc S, Ellemberg D: Neuropsychological and neurophysiological assessment of sport concussion in children, adolescents and adults. Brain Inj 26:211-220, 2012

4. Baker JG, Leddy JJ, Darling SR, Shucard J, Makdissi M, Willer BS: Gender differences in recovery from sportsrelated concussion in adolescents. Clin Pediatr (Phila) 55:771-775, 2016

5. Bell DR, Guskiewicz KM, Clark MA, Padua DA: Systematic review of the balance error scoring system. Sports Health 3:287-295, 2011

6. Broglio SP, Kontos AP, Levin H, Schneider K, Wilde EA, Cantu RC, et al: National Institute of Neurological Disorders and Stroke and Department of Defense Sport-Related Concussion Common Data Elements Version 1.0 Recommendations. J Neurotrauma 35:2776-2783, 2018

7. Chase D, Schatz P, Smyk N, Franks RR: The stability of engagement over comprehensive neuropsychological assessment in student athletes diagnosed with sports related concussion. Dev Neuropsychol 43:345-355, 2018

8. Connery AK, Peterson RL, Baker DA, Kirkwood MW: The impact of pediatric neuropsychological consultation in mild traumatic brain injury: a model for providing feedback after invalid performance. Clin Neuropsychol 30:579-598, 2016

9. Corwin DJ, Zonfrillo MR, Master CL, Arbogast KB, Grady MF, Robinson RL, et al: Characteristics of prolonged concussion recovery in a pediatric subspecialty referral population. J Pediatr 165:1207-1215, 2014

10. Ellis MJ, Cordingley DM, Vis S, Reimer KM, Leiter J, Russell K: Clinical predictors of vestibulo-ocular dysfunction in pediatric sports-related concussion. J Neurosurg Pediatr 19:38-45, 2017

11. Erlanger D, Kaushik T, Cantu R, Barth JT, Broshek DK, Freeman JR, et al: Symptom-based assessment of the severity of a concussion. J Neurosurg 98:477-484, 2003

12. Filippi CG, Sanelli PC: Pediatric traumatic brain injury: common data elements to inform diagnosis, neuroimaging, and outcome metrics. J Pediatr Neuroradiol 5:32-37, 2016

13. Guskiewicz KM: Assessment of postural stability following sport-related concussion. Curr Sports Med Rep 2:24-30, 2003

14. Hajek CA, Yeates KO, Taylor HG, Bangert B, Dietrich A, Nuss KE, et al: Agreement between parents and children on ratings of post-concussive symptoms following mild traumatic brain injury. Child Neuropsychol 17:17-33, 2011

15. Henry LC, Elbin RJ, Collins MW, Marchetti G, Kontos AP Examining recovery trajectories after sport-related concussion with a multimodal clinical assessment approach. Neurosurgery 78:232-241, 2016

16. Heyer GL, Schaffer CE, Rose SC, Young JA, McNally KA, Fischer AN: Specific factors influence postconcussion symptom duration among youth referred to a sports concussion clinic. J Pediatr 174:33-38, 38.e1-38.e2, 2016

17. Howell DR, Mannix RC, Quinn B, Taylor JA, Tan CO, Meehan WP III: Physical activity level and symptom duration are not associated after concussion. Am J Sports Med 44:1040 1046, 2016

18. Howell DR, O'Brien MJ, Raghuram A, Shah AS, Meehan WP III: Near point of convergence and gait deficits in adolescents after sport-related concussion. Clin J Sport Med 28:262-267, 2018 
19. Howell DR, Osternig LR, Chou LS: Adolescents demonstrate greater gait balance control deficits after concussion than young adults. Am J Sports Med 43:625-632, 2015

20. Howell DR, Zemek R, Brilliant AN, Mannix RC, Master CL, Meehan WP III: Identifying persistent postconcussion symptom risk in a pediatric sports medicine clinic. Am J Sports Med 46:3254-3261, 2018

21. Iverson G: Predicting slow recovery from sport-related concussion: the new simple-complex distinction. Clin J Sport Med 17:31-37, 2007

22. Iverson GL, Gardner AJ, Terry DP, Ponsford JL, Sills AK, Broshek DK, et al: Predictors of clinical recovery from concussion: a systematic review. Br J Sports Med 51:941-948, 2017

23. Jacobson GP, McCaslin DL, Piker EG, Gruenwald J, Grantham S, Tegel L: Insensitivity of the "Romberg test of standing balance on firm and compliant support surfaces" to the results of caloric and VEMP tests. Ear Hear 32:e1-e5, 2011

24. King LA, Horak FB, Mancini M, Pierce D, Priest KC, Chesnutt $\mathrm{J}$, et al: Instrumenting the balance error scoring system for use with patients reporting persistent balance problems after mild traumatic brain injury. Arch Phys Med Rehabil 95:353-359, 2014

25. Kirkwood MW, Peterson RL, Connery AK, Baker DA, Forster $\mathrm{J}$ : A pilot study investigating neuropsychological consultation as an intervention for persistent postconcussive symptoms in a pediatric sample. J Pediatr 169:244-249, 249.el, 2016

26. Kirkwood MW, Peterson RL, Connery AK, Baker DA, Grubenhoff JA: Postconcussive symptom exaggeration after pediatric mild traumatic brain injury. Pediatrics 133:643-650, 2014

27. Lau BC, Kontos AP, Collins MW, Mucha A, Lovell MR: Which on-field signs/symptoms predict protracted recovery from sport-related concussion among high school football players? Am J Sports Med 39:2311-2318, 2011

28. Lynall RC, Laudner KG, Mihalik JP, Stanek JM: Concussionassessment and -management techniques used by athletic trainers. J Athl Train 48:844-850, 2013

29. Majerske CW, Mihalik JP, Ren D, Collins MW, Reddy CC, Lovell MR, et al: Concussion in sports: postconcussive activity levels, symptoms, and neurocognitive performance. J Athl Train 43:265-274, 2008

30 Master CL, Master SR, Wiebe DJ, Storey EP, Lockyer JE, Podolak OE, et al: Vision and vestibular system dysfunction predicts prolonged concussion recovery in children. Clin J Sport Med 28:139-145, 2018

31. McCrea M, Barr WB, Guskiewicz K, Randolph C, Marshall SW, Cantu R, et al: Standard regression-based methods for measuring recovery after sport-related concussion. J Int Neuropsychol Soc 11:58-69, 2005

32. McCrory P, Feddermann-Demont N, Dvořák J, Cassidy JD, McIntosh A, Vos PE, et al: What is the definition of sportsrelated concussion: a systematic review. Br J Sports Med 51:877-887, 2017

33. McCrory P, Meeuwisse W, Dvořák J, Aubry M, Bailes J, Broglio S, et al: Consensus Statement on Concussion in Sportthe 5th International Conference on Concussion in Sport held in Berlin, October 2016. Br J Sports Med 51:838-847, 2017

34. Meehan WP III, d'Hemecourt P, Collins CL, Comstock RD: Assessment and management of sport-related concussions in United States high schools. Am J Sports Med 39:23042310, 2011

35. Meehan WP III, Mannix R, Monuteaux MC, Stein CJ, Bachur RG: Early symptom burden predicts recovery after sport-related concussion. Neurology 83:2204-2210, 2014

36. Meehan WP III, Mannix RC, O'Brien MJ, Collins MW: The prevalence of undiagnosed concussions in athletes. Clin J Sport Med 23:339-342, 2013
37. Meehan WP III, Mannix RC, Stracciolini A, Elbin RJ, Collins MW: Symptom severity predicts prolonged recovery after sport-related concussion, but age and amnesia do not. J Pediatr 163:721-725, 2013

38. Meehan WP III, O'Brien MJ, Geminiani E, Mannix R: Initial symptom burden predicts duration of symptoms after concussion. J Sci Med Sport 19:722-725, 2016

39. Merritt VC, Arnett PA: Premorbid predictors of postconcussion symptoms in collegiate athletes. J Clin Exp Neuropsychol 36:1098-1111, 2014

40. Miller JH, Gill C, Kuhn EN, Rocque BG, Menendez JY, O'Neill JA, et al: Predictors of delayed recovery following pediatric sports-related concussion: a case-control study. J Neurosurg Pediatr 17:491-496, 2016

41. Pearce KL, Sufrinko A, Lau BC, Henry L, Collins MW, Kontos AP: Near point of convergence after a sport-related concussion: measurement reliability and relationship to neurocognitive impairment and symptoms. Am J Sports Med 43:3055-3061, 2015

42. Provance AJ, Terhune EB, Cooley C, Carry PM, Connery AK, Engelman GH, et al: The relationship between initial physical examination findings and failure on objective validity testing during neuropsychological evaluation after pediatric mild traumatic brain injury. Sports Health 6:410-415, 2014

43. Reneker JC, Hassen A, Phillips RS, Moughiman MC, Donaldson M, Moughiman J: Feasibility of early physical therapy for dizziness after a sports-related concussion: a randomized clinical trial. Scand J Med Sci Sports 27:2009-2018, 2017

44. Zemek R, Barrowman N, Freedman SB, Gravel J, Gagnon I, McGahern C, et al: Clinical risk score for persistent postconcussion symptoms among children with acute concussion in the ED. JAMA 315:1014-1025, 2016

45. Zuckerman SL, Lee YM, Odom MJ, Solomon GS, Forbes JA, Sills AK: Recovery from sports-related concussion: days to return to neurocognitive baseline in adolescents versus young adults. Surg Neurol Int 3:130, 2012

46. Zuckerman SL, Yengo-Kahn AM, Buckley TA, Solomon GS, Sills AK, Kerr ZY: Predictors of postconcussion syndrome in collegiate student-athletes. Neurosurg Focus 40(4):E13, 2016

\section{Disclosures}

Dr. Howell receives research support not related to this study from the Eunice Kennedy Shriver National Institute of Child Health \& Human Development (R03HD094560) and the National Institute of Neurological Disorders and Stroke (R01NS100952 and R41NS103698) as well as from a research contract between Boston Children's Hospital, Cincinnati Children's Hospital Medical Center, and ElMindA Ltd.

\section{Author Contributions}

Conception and design: all authors. Acquisition of data: Howell, Potter, Provance, JC Wilson. Analysis and interpretation of data: all authors. Statistical analysis: Howell. Drafting the article: Howell, JC Wilson. Critically revising the article: all authors. Reviewed submitted version of manuscript: all authors. Approved the final version of the manuscript on behalf of all authors: Howell. Administrative/technical/material support: Howell, JC Wilson. Study supervision: Howell, Kirkwood, PE Wilson, Provance, JC Wilson.

\section{Correspondence}

David R. Howell: Sports Medicine Center, Children's Hospital Colorado, University of Colorado School of Medicine, Aurora, CO.david.howell@ucdenver.edu. 